\title{
TSD FACILITIES LOCATION AND ENVIRONMENTAL JUSTICE
}

\author{
Stephan J. Goetz and Donald J. Kemlage*
}

\begin{abstract}
After controlling for cost- and demand-related factors affecting the profitability of operating hazardous waste treatment, storage and disposal (TSD) facilities, we find that higher shares of minority population and poverty rates are associated with a statistically higher probability that one or more TSD facilities are present in a county. Evidence regarding the relationship between minorities and the number of TSD facilities per capita is mixed. An inverse Kuznet's U-type effect is found to exist between per capita income and the probability of TSD location.
\end{abstract}

\section{INTRODUCTION}

The term "environmental injustice" has been used recently to describe situations in which costs of environmental pollution are spread unevenly over the population. Especially in the legal profession, the term refers to higher exposure of minorities and low-income populations to negative externalities associated with living next to toxic waste sites or manufacturing industries that are especially prone to polluting (e.g., Brown 1993; Keeva 1994; Been 1994). Economists have previously focused on trade-offs among policy instruments for controlling environmental externalities (Hahn and Stavins 1992; Helfand 1991), including measurement of benefits and costs of environmental programs and willingness to pay for abatement and effects of abatement on the consumption of market goods across income groups (Cropper and Oates 1992). However, they have paid less attention to identifying broader socioeconomic factors associated with the location of hazardous waste sites.

Using computable general equilibrium models, input-output models or expenditure budgets, numerous studies have concluded that income distributional effects of environmental programs are regressive (Robison 1985; Gianessi, Peskin and Wolf 1979; Snow 1975; Cropper and Oates 1992). Others have used the presence of toxic waste management facilities as a determinant of quality of life (e.g., Blomquist, Berger and Hoehn 1988). To our knowledge, no previous study systematically identifies, at the national level and using an underlying economic

\footnotetext{
*Associate Professor, Department of Agricultural Economics, University of Kentucky; and technical analyst at ESRI, California (and former Research Associate in the same department). With the usual caveat, the authors gratefully acknowledge helpful comments by David Debertin, Craig Infanger and Lionel Williamson, as well as three reviewers.
} 
model, the degree of association between toxic waste facilities location and concentrations of minorities and low income groups.

Perhaps the most widely cited study on this topic is one commissioned by the United Church of Christ (1987). In the study, discriminant analysis was used to test for statistical relationships between uncontrolled hazardous waste locations and mean household income, minority shares, mean values of owner-occupied homes and local hazardous waste production. A zip code-level analysis of over 400 hazardous waste sites indicated race was more strongly correlated with residential proximity to waste facilities than were socioeconomic factors. Furthermore, areas with more than one facility had a larger share of minorities residing nearby than did areas with only one facility. The authors caution (p. 11) that their ". . . study was not designed to show cause and effect." In the discriminant analysis, housing value and hazardous waste generated were found not to be statistically significant. One problem with this study is the limited set of socioeconomic variables included; another is the fact that housing (or land) values and toxic facilities location are likely to be simultaneously determined.

Detailed case studies have been carried out for selected major cities to examine the relationship between race and environmental waste (e.g., Mohai and Bunyan, 1992). A recent U.S. EPA (1992, vol. 1, p. 3) study concludes that "[r]acial minority and low-income populations experience higher than average exposures to ... hazardous waste facilities ...." This conclusion is in turn based on a 1982-83 GAO study of landfills in Alabama, South Carolina, and North Carolina containing hazardous wastes. Simple averages were calculated for the percent of census area population that was black or living below the poverty line. Of impoverished residents living near hazardous waste sites, between 90 and 100 percent were African-Americans (U.S. EPA, 1992, vol. 2, pp. 7-8). An extensive annotated bibliography is contained in Weintraub (1994).

In this paper we specify a county-level model of EPA-registered hazardous waste treatment, storage and disposal (TSD) facilities locations across 3,111 continental U.S. counties. Owners of these facilities are assumed to seek out sites with the goal of maximizing profits, taking into account revenues and costs of operation. Under Subtitle C of the 1976 Resource Conservation and Recovery Act, TSD facilities must be registered with the EPA, which is responsible for ensuring that technical standards are met to protect human health and the environment (U.S. EPA, 1993). TSD sites examined here exclude facilities on the National Priority List (sites at which accidents have occurred rendering the area unsafe for humans, the worst of which are commonly known as Superfund sites), and they exclude the approximately 266,000 sites nationwide (U.S. EPA, 1993) from which hazardous wastes originate. However, these facilities constitute the intermediate storage and final "resting" sites for toxic waste, and they are there- 
fore of concern over the long term. The central purpose of the analysis is to determine whether higher shares of minorities and low income groups in a county are associated with higher or lower odds that one or more TSD sites are present, after controlling for cost- and revenue-related variables.

Two caveats are needed before discussing the theoretical motivation for the equation specifying the location of TSD facilities. First, a county-level analysis is unable to detect relationships between waste facilities locations and minority shares within counties. Also, a TSD facility may be located close to or on a county line, and be adjacent to a minority-dominated community in a bordering county. This point is discussed in more detail at the end of the Results section. Second, minorities and those living in poverty may migrate to communities with TSD sites to take advantage of lower-cost housing and (potentially) higher-paying jobs associated with the waste facility. Alternatively, higher-income individuals have the mobility to move out of neighborhoods with nearby TSD facilities. In this study, we assume that minorities and the poor locate primarily based on historical patterns, and do not deliberately seek out neighborhoods with TSD sites to purchase homes. In addition, we control for (endogenous) housing costs using predicted county-level median housing values in the equation modeling TSD facilities location.

Ideally, one would use TSD location data from two different periods and focus specifically on locations of new facilities as a function of conditions prevailing in the initial period. Unfortunately, data limitations prevent us from pursuing this option. If, in addition, a theory were developed of where minorities or the poor locate over time, a simultaneous equations model could be estimated. Thus, as more data become available over time, it will also be feasible to study the effect of TSD locations on local socioeconomic conditions. A related discussion appears in Been (1994, pp. 1392-7).

\section{A TSD FACILITIES LOCATION MODEL}

Owners of TSD facilities are assumed to maximize profits subject to a constraint representing community resistance to siting of such facilities. Factors $\left(z_{i}\right)$ affecting profits in county $i$ include (on the demand side) revenue earned by operating TSD facilities for toxic waste storage and disposal purposes, as reflected in each county's industrial mix, which is assumed to be exogenous and proxied here by a vector of earnings indicator variables in $j$ industries $\left(\Sigma_{i j} I N D_{i j}\right)$ that are especially prone to generating toxic wastes. These industries are selected on the basis that the share of pollution abatement gross operating costs allocated to hazardous solid waste is at least 95 percent of that allocated to non-hazardous 
solid waste (U.S. Dept. of Commerce, 1993, Table 379). In addition, variables reflecting the relative importance of military and agricultural employment in each county are included as controls. ${ }^{1}$ Military activity is hypothesized to increase the demand for TSD sites for disposal and storage of residues from chemical and other weapons, while the opposite is expected to be the case for agricultural activity. Although chemicals are used extensively in agricultural production, they are not necessarily stored or disposed of in the rural farming communities in which they are applied. An obvious direct linkage exists between hazardous waste-generating industrial activity and the demand for TSDs. However, consumers in counties where employment or earnings in such industries are substantial may also be more likely to accept such facilities in their communities because of employment and tax revenue consequences. Thus, operators earn higher net revenues and face less resistance to locating their facilities in those counties.

Costs of operating TSD facilities are hypothesized to depend on the cost of land, as proxied by median housing values $\left(M H V_{i}\right),{ }^{2}$ and access to U.S. interstates $\left(H I W Y_{i}\right)$ and Class I commercial railroads $\left(R A I L_{i}\right)$ as low-cost means of transporting waste. We also include an urban/rural indicator variable $\left(U R B N_{i}\right)$ to capture agglomeration economies beyond those that result from locating close to industries demanding TSD services $\left(\Sigma_{i j} I N D_{i j}\right)$. These economies capture inter- and intra-industry-specific cost savings available in metropolitan areas (such as lowercost utilities and other services). In addition, population density $\left(D E N S_{i}\right)$ is included in the regression. Higher concentrations of humans are expected to deter the nearby location of hazardous waste management facilities by raising costs of operation. For example, environmental protection laws are not only likely to be more stringent in such cases, but also more rigidly enforced. ${ }^{3}$

Independent variables measuring community resistance to TSD location can be divided into $(a)$ knowledge and $(b)$ income factors. A vector of $k$ educational attainment categories $\left(\Sigma_{i k} E D U C_{i k}\right)$ is included under the hypothesis that individuals with higher levels of education are more likely to resist the installation of new facilities (and avoid residing next to a TSD site), ceteris paribus, because their costs of acquiring information about potential adverse health effects of locating next to such sites are lower (Deacon and Shapiro 1975; Fischel 1979; Nelson and Phelps 1966; Schultz 1975; Goetz, Debertin and Pagoulatos 1995). Thus, greater educational attainment of the resident population is hypothesized to raise costs of establishing a TSD facility and reduce the likelihood that they are located in a county. Per capita income $\left(I N C_{i}\right)$ measures the ability of individuals to engage in defensive strategies that prevent TSD facilities from locating nearby (Mohai and Bunyan 1992). However, to the extent that higher incomes are associated with greater consumption of goods requiring TSD sites, it is plausible that lower-income communities have fewer nearby TSD sites. Therefore, the 
effect of income needs to be determined empirically. To test for the existence of a Kuznet's inverse-U effect (see Selden and Song 1994) between income and TSD location, a quadratic income term is included in the regression.

After controlling for each of these revenue- and cost-related variables affecting the profitability of operating a TSD facility, we may test whether any variation remains in the dependent variable (reflecting the presence of TSD facilities) that is associated with the share of different minorities and the poverty rate in the county. If these population groups offer less opposition to the nearby location of TSD facilities, ceteris paribus, then costs to owners of locating in these counties would be lower and profits higher. Thus, our null hypothesis is that, after controlling for revenue- and cost-related shifters of the profit function, including resistance as measured by educational attainment and income, individual coefficient estimates on a vector of $l$ racial minority proportions $\left(\Sigma_{i l} R A C E_{i l}\right)$ and the poverty rate $\left(P O V_{i}\right)$ do not differ statistically from zero.

Given the censored nature of the data used in this study, where $n_{1}=1,132$ counties had at least one TSD facility (TSD $\geq 1$ ) while $n_{2}=1,979$ counties had none ( $T S D=0)$, Tobit maximum likelihood estimation is appropriate for generating unbiased coefficients. However, the Tobit method assumes that a given regressor jointly determines the probability that an event occurs (one or more TSD sites are present in the county) and the intensity of that event (measured, in this case, as the number of TSD sites per capita). ${ }^{4}$ Thus, the Tobit method does not take advantage of all of the information contained in the sample.

Two equations are specified to fully model the presence of TSD facilities. The first is a probit equation, which predicts the likelihood that county $i$ has a TSD facility, as a function of county characteristics $z_{i}$ :

$$
\operatorname{Prob}\left(T S D_{i} \geq 1\right)=\int_{-\infty}^{\beta_{1} z_{i}} \phi(\mathrm{x}) \mathrm{dx}, \quad i \in \mathrm{n}_{1} \cup n_{2},
$$

and the second is a selection equation predicting the number of TSD's per capita $\left(\right.$ pop $\left._{i}\right)$ in county $i$, conditional on $i \in n_{1}$ :

$$
\frac{T S D_{i}}{\text { pop }_{i}}=t s d_{i}=\beta_{2} z_{i}+\gamma \frac{\phi\left(\beta_{1} z_{i}\right)}{\Phi\left(\beta_{1} z_{i}\right)}+\epsilon_{\mathrm{i}}, \quad \forall \mathrm{i} \in \mathrm{n}_{\mathrm{i}}
$$

Here $\phi$ and $\Phi$ denote the marginal and cumulative normal distribution functions, respectively, $\phi(\bullet) / \Phi(\bullet)$ is the inverse Mill's ratio calculated from (1), and $\gamma$ is the corresponding coefficient. ${ }^{5}$ This equation captures the intensity of exposure to TSD facilities per capita, as opposed to the more crude (discrete) measure of 
whether one or more facilities are present. If some or all of the processes that determine whether or not a TSD facility is present are the same as those determining the number of facilities per capita, then ignoring the inverse Mill's ratio in (2) leads to selection bias. The same regressors $(z i)$ are used in both equations. This provides flexibility for some variables to have different effects on the probability that TSD facilities are present in a county, as opposed to the number of facilities. The probit model allows "threshold" effects to be identified, which must first be overcome before one or more TSD facilities can be established in a county.

\section{DATA}

The data on TSD facilities were obtained over the Internet from the FTP server at the Office of Solid Waste in the EPA (FTP.EPA.GOV), and reflect facilities locations as of 1994. The data set contains complete addresses of each facility, including a facility ID number, a contact name and a phone number, as well as a designation as to whether the facility is for treatment and storage only, land disposal, or incineration. Thus, it would in principle have been possible to carry out the analysis at the zip code- or census tract-levels. However, the decision was made to use counties as the unit of analysis because a TSD's main office may be in one ZIP code area, while the actual facility is in another area within the same county. Also, some of the exogenous variables are available only at the county level.

After limiting the analysis to the continental U.S., we obtained 3,111 observations. The EPA data were merged at the county level with 1990 U.S. Census of Population data, as well as 1992 data from the U.S. Department of Transportation on interstate highways and the Federal Railroad Administration on Class I railroads passing through each county. The Geographic Information System (GIS) software TransCAD $\odot$ was used to designate a county as having U.S. interstate highway access $\left(H I W Y_{i}=1\right)$ only if a highway passes through the county and a ramp onto and off the highway exists in that county. Similarly, the indicator variable for Class I railroads was set equal to 1 only if a known loading and unloading junction exists in the county. Summary statistics for variables used in the regressions are reported in the Appendix Table.

Figure 1 shows locations of TSD facilities aggregated across counties. Facilities are concentrated in the East-North-Central and Middle-Atlantic states, as well as in Iowa, Texas and California. These concentrations largely reflect location patterns of petrochemical and petroleum-refining industries along the Eastern Seaboard and Texas and Louisiana, as well as activity in automotive-, steel- and rubber-producing industries in states bordering the Great Lakes. The 
FIGURE 1

Total Number of Waste Treatment, Storage and Disposal Facilities per County

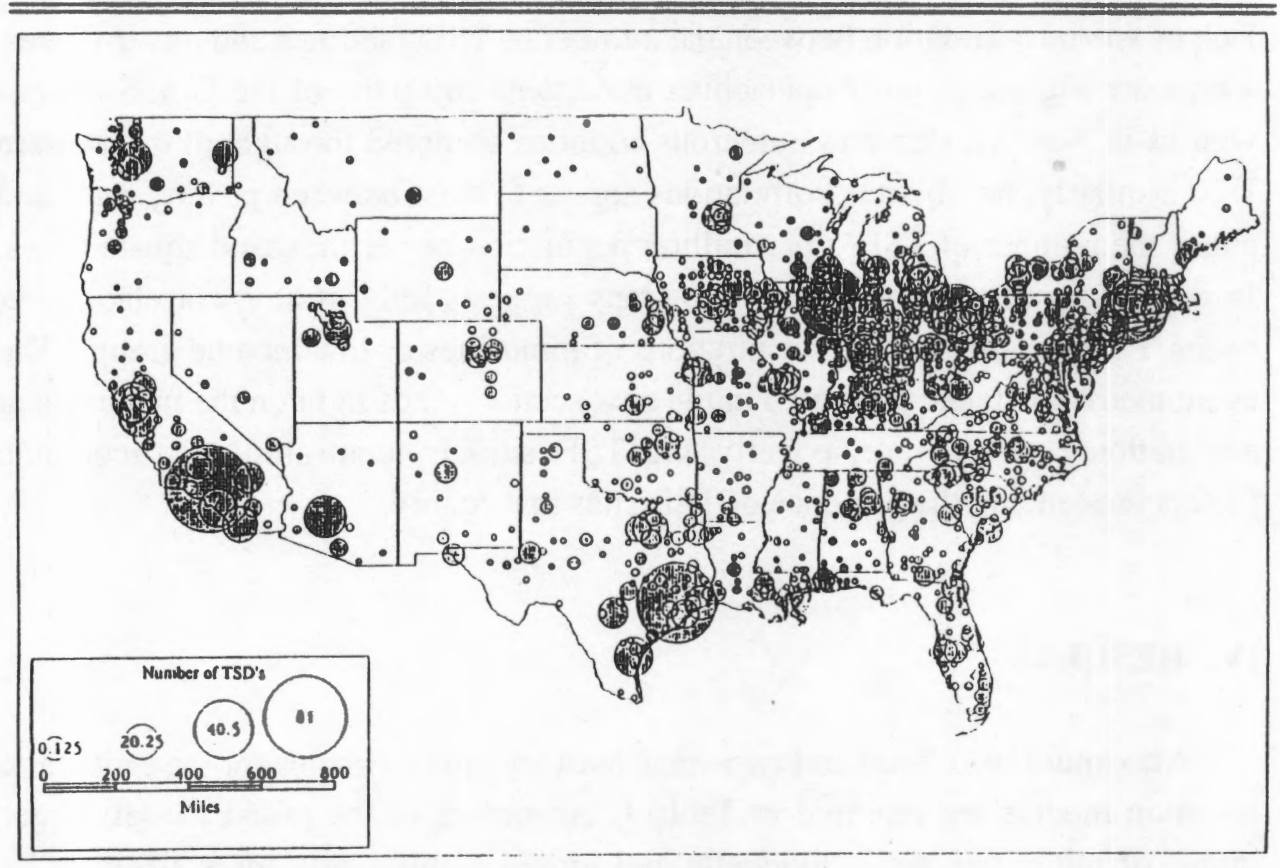

South, in which many African-Americans reside, does not appear to have strong concentrations of TSD facilities. On the surface, the absence of such concentrations suggests a lack of environmental injustice with respect to that minority. Furthermore, other minorities-American Indians, Asian and Pacific Islanders and "Other Races"-also appear to be concentrated in counties where TSD facilities are not present. For example, American-Indians are mainly clustered in U.S. Mountain states as well as Oklahoma and, to a lesser degree, in West North Central states. Asian and "Other Race" minorities are, with the exception of Idaho and Nevada, located mainly in states along the western U.S. coast and the Mexican border. $^{6}$

Relatively large concentrations of TSD facilities per million population are found in Iowa, Kentucky and Virginia, which similarly suggests a lack of environmental injustice, since these areas do not have large concentrations of minorities. In comparing concentrations in the eastem and western U.S., it is important to note that most counties are larger in the western U.S. Indeed, a plot of TSD sites per thousand square miles reveals high TSD densities along the East Coast in the New York primary metropolitan statistical area (including New Jersey and Connecticut), as well as around Chicago and in or near many of the larger cities in the eastern half of the U.S. In all of the western U.S., there are only three clusters of 
counties with high TSD densities per square mile: two are in California (the San Francisco Bay area and Los Angeles), and one is in Utah (Salt Lake City).

A map of poverty rates across the United States also generally suggests a lack of spatial correlation between the number of TSD facilities and poverty rates, which are highest in the Appalachian mountains and parts of the U.S. South, as well as in New Mexico and numerous counties scattered throughout the western U.S. Similarly, no obvious correlations appear to exist between poverty rates and either the number of TSD's per million population or per thousand square miles. In general, inspection of appropriate maps suggests little, if any, correlation between TSD locations and concentrations of minorities or low income groups. The econometric evidence presented in the next section sheds light on the independent association between race, poverty and TSD sites by controlling for economic factors influencing the presence of TSD sites in a county.

\section{RESULTS}

Maximum likelihood and two-stage least squares estimates for the probit and selection models are reported in Table 1. According to the probit model, larger shares of minorities are individually and jointly significantly more likely to be associated with the presence of one or more TSD facilities in the county, ceteris paribus, than is the case for larger shares of non-minorities. Figure 2 shows how $\operatorname{Prob}\left(T S D_{Z}{ }^{1}\right)$ changes as the share of each minority increases. Among minorities, African-Americans were the least likely to have one or more TSD facilities in their counties, given the same percentage share of the county population. When a minority constituted one-third of the county population, the probability of having a TSD facility present was 38.0 percent for African-Americans, 50.0 percent for American-Indians; 61.7 percent for other minorities of other races, and 100 percent for Asians.

The probit estimation yields a positive coefficient estimate for the linear per capita income term, and a negative coefficient for the quadratic term, suggesting that an inverse- $U$ effect exists between TSD facilities and income. This implies that both low and high income groups are less likely to reside in counties with TSD facilities than are middle-income groups, which may suggest that low income groups on average consume fewer goods requiring large amounts of toxic waste disposal, while high-income groups are able to avoid having TSDs locate in their neighborhoods. The maximum on the inverse- $U$ curve occurs at $I N C^{\max }=\$ 21,500$. Only 21 counties $(0.7$ percent) have incomes above this level. Thus, most counties are located on the upward sloping portion of the Kuznets 
Estimation Results for TSD Facilities Locations

\begin{tabular}{|c|c|c|c|c|c|}
\hline \multirow[b]{2}{*}{ Variable } & & \multicolumn{2}{|c|}{$\begin{array}{c}M L E \\
\operatorname{Prob}\left(T S D_{i 21}\right)\end{array}$} & \multicolumn{2}{|c|}{$\begin{array}{l}\text { 2SLS Selection Model } \\
\text { depend. var.=tsdi }\end{array}$} \\
\hline & & $\beta_{1}$ & s.e. $\left(\beta_{1}\right)$ & $\beta_{2}$ & s.e. $\left(\boldsymbol{\beta}_{2}\right)$ \\
\hline Constant & & $-4.845 * * *$ & 0.943 & -0.363 & 0.920 \\
\hline \multirow[t]{8}{*}{$\Sigma_{i j} I N D_{i j}$} & Paper \& Allied Products & $0.272 * * *$ & 0.065 & -0.022 & 0.048 \\
\hline & Petroleum \& Coal Products & $0.437 * * *$ & 0.066 & $0.135 * * *$ & 0.037 \\
\hline & Primary Metals Industries & $0.317 * * *$ & 0.064 & $0.051 \dagger$ & 0.033 \\
\hline & Fabricated Metals Products & $0.164 * *$ & 0.080 & $-0.171 * * *$ & 0.064 \\
\hline & Machinery, excl. electrical & $0.197 * *$ & 0.095 & $-0.485^{* * *}$ & 0.173 \\
\hline & Transport. Equipment & $0.219 * * *$ & 0.062 & $-0.056^{*}$ & 0.033 \\
\hline & Military employment & $0.064 * * *$ & 0.015 & 0.0004 & 0.0068 \\
\hline & Agricultural employment & $-0.084 * * *$ & 0.014 & $0.059 *$ & 0.031 \\
\hline$M H V_{i}$ & Median Housing Value $\ddagger$ & $-9.5 e-06 * * *$ & $2.6 e-06$ & $-4.0 e-06 * * *$ & $9.7 e-07$ \\
\hline$H I W Y_{i}$ & Interstate Access & $0.180 * * *$ & 0.062 & 0.014 & 0.054 \\
\hline$R A I L_{i}$ & Railroad Access & $0.348 * * *$ & 0.061 & $0.081 \dagger$ & 0.058 \\
\hline$U R B N_{i}$ & Metropolitan Area & $0.173 * *$ & 0.083 & $-0.080 * *$ & 0.034 \\
\hline$D E N S_{i}$ & Population Density & $-6.7 e-04$ & $1.4 \mathrm{e}-03$ & $6.6 \mathrm{e}-04$ & $4.2 e-04$ \\
\hline \multirow[t]{6}{*}{$\Sigma_{i k} E D U C_{i k}$} & High School Dropouts & $-2.465^{*}$ & 1.368 & -0.923 & 1.250 \\
\hline & High School Diploma & $1.419 *$ & 0.762 & 0.676 & 0.496 \\
\hline & Some College & -1.143 & 1.000 & 0.997 & 0.750 \\
\hline & Associate's Degree & $4.195 * *$ & 1.949 & -1.524 & 1.053 \\
\hline & Bachelor's Degree & $-3.583 *$ & 1.959 & -0.881 & 1.575 \\
\hline & Graduate/Professional Degree & 0.525 & 1.946 & -0.097 & 0.865 \\
\hline \multirow[t]{2}{*}{$I N C_{i}$} & Income per capita & $4.5 \mathrm{e}-04^{* * *}$ & $9.5 e-05$ & $1.1 e-04 * *$ & $4.9 e-05$ \\
\hline & Income per capita squared & $-1.0 e-08 * * *$ & $2.7 e-09$ & $-1.8 \mathrm{e}-09+$ & $1.3 \mathrm{e}-09$ \\
\hline \multirow[t]{4}{*}{$\Sigma_{i l R A C E_{i l}}$} & African-American & $0.709 * *$ & 0.299 & $0.268 \dagger$ & 0.185 \\
\hline & American Indian & $1.514 * *$ & 0.600 & -0.251 & 0.283 \\
\hline & Asian/Pacific Islander & $28.76 * * *$ & 4.492 & $2.765 * * *$ & 0.829 \\
\hline & Other minority & $2.482 * *$ & 0.820 & 0.126 & 0.617 \\
\hline$P_{i}$ & Poverty Rate & $1.974 * *$ & 1.018 & 0.280 & 0.620 \\
\hline $\boldsymbol{\gamma}$ & & & & $0.413 * * *$ & 0.138 \\
\hline Sample size & & 3,111 & & 1,132 & \\
\hline$\chi^{2}$-test (26) & & $1,340.8 * * *$ & & & \\
\hline Adjusted $R^{2}$ & & & & 35.1 & \\
\hline
\end{tabular}

Significance levels: $*=10$ percent, ${ }^{* *}=5$ percent, ${ }^{* * *}=1$ percent or lower (two-tailed tests); $\uparrow=10$ percent (onetailed test)

Standard errors in the selection model are corrected for heteroscedasticity.

$\ddagger$ Predicted value from an auxiliary regression; see footnote to Appendix table. 
curve. Higher poverty rates, independent of average county income, are associated with significantly higher odds that $T S D_{i}>0$.

The presence of any of the industries generating proportionally large amounts of toxic wastes is associated with a significantly higher likelihood of a TSD site's being located in a county. As transportation regulations for hazardous waste become more stringent over time and shipping consequently becomes more costly, this phenomenon may be reinforced as less waste is moved across county lines (see also Padgett 1992). Similarly, relatively higher military employment is associated with significantly higher odds of TSD sites being located in a county. The larger the number of jobs in agricultural services, the lower the odds that one or more TSD facilities are present, as expected.

The coefficient estimate for median housing values is statistically significant and negative, as expected. This likely reflects both a higher average cost of land in counties with higher MHVs, and more latitude by wealthy homeowners to engage in defensive strategies preventing the nearby location of TSD facilities (i.e., the "not in my back yard" (NIMBY) syndrome), which in turn also raises transactions costs of owners of TSD facilities seeking to establish new locations. Urban counties, and those with highway or railroad access are significantly more likely to have TSD facilities. The latter results likely reflect reduced costs of transporting hazardous wastes, although transportation may become less important over time for reasons noted in the previous paragraph.

Counties with more highly educated populations, as reflected in the proportion of residents 25 years and older having completed four-year college degrees, are, as expected, less likely to have TSD facilities, according to the probit model. However, having a larger share of adults with graduate or professional degrees does not significantly change the odds that a TSD site is present. This may reflect effects of higher employment concentration in professions associated with the generation of hazardous wastes, such as biohazards in the medical profession. Counties with larger shares of high school dropouts relative to those with fewer than nine years of education are less likely to contain TSD facilities, while the opposite is true for higher shares of high school diploma holders.

Results for the selection model in Table 1 suggest that only the share of minorities with an Asian or Pacific Islander origins is associated with a statistically significant higher number of TSD facilities per capita in a county. It should be noted that this minority group appears in only a few states in significant proportions. For African-American minorities, this association is significant only in a one-tailed test at the 10 percent level. Higher shares of the other two minorities in the county population, in contrast, are not associated with higher concentrations of TSDs per capita. Thus, in terms of exposure of individuals to a higher number of TSDs per capita, conditional on such facilities being present, the statistical 
FIGURE 2

Probability of TSD Facilities Location by Race

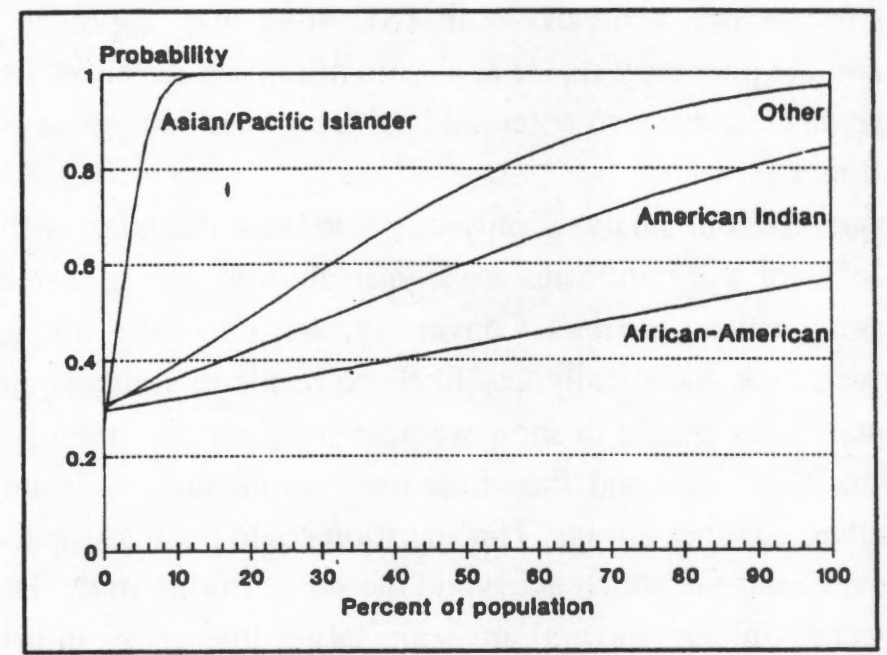

evidence reveals a significant association for Asian or Pacific Islanders, a weaker association for African-Americans, and no association for American Indians and "Other" minorities. Again, because of data limitations discussed earlier, these results have to be interpreted with caution.

The selection model also reveals that the association between industrial sector variables and TSDs per capita $\left(t s d_{i}\right)$ and $\operatorname{Prob}\left(T S D_{i}\right)$ ) differs, so that $\beta_{1} \neq \beta_{2}$. In particular, a greater share of agricultural employment is associated with a reduced $\operatorname{Prob}\left(T S D_{i} \geq 1\right)$, but higher $t s d_{i}$ in the selection model, conditional on TSD facilities being present. The fabricated metals products, machinery (excluding electrical) and transportation equipment industries are each associated with fewer TSDs per capita, which may reflect different needs for TSD disposal sites in these industries. In contrast, a higher share of military employment is not associated with a larger or smaller number of TSD facilities per capita. In the selection equation, median housing value retains the expected sign, while income per capita continues to exhibit an inverse- $U$ shaped relationship with $t s d_{i}$. In this case, the turning point on the Kuznets curve is reached at a per capita income of $\$ 29,400$ (which is outside the data range).

A reviewer has pointed out that the Public Health Service's Agency for Toxic Substance and Disease Registry normally considers a $0.5-1$ mile radius 
around toxic sites on the National Priorities List (which are more toxic than TSD sites) when studying potential health hazards and exposure to toxins. In comparison, the average land area of the counties studied here is 952 square miles ${ }^{2}$, which corresponds to a radius of 17.4 miles (assuming circular counties). Thus, especially in western States, where counties are large, population density (which we control for in this analysis) near TSD sites may approach zero, so that minorities and the poor may reside at a "safe minimum distance" from the site, or not face a greater exposure to potential health hazards than other groups residing in adjacent counties.

Consequently, our analysis only suggests that counties with greater concentrations of poor and minorities are significantly more likely to contain one or more TSD sites, ceteris paribus. Conversely, non-minorities and individuals not living in poverty are statistically less likely to reside in counties containing TSD sites. The analysis is unable to show whether the poor and minorities on average live closer to TSD sites and thus face more immediate exposure to potential health risks than do other groups. This question could be investigated using a census block-level analysis, which is beyond the scope of this study. However, to the extent that census blocks in rural areas are larger than those in urban areas, the problems identified here at the county-level using census data could also arise at the census block-level.

\section{v. SUMMARY AND CONCLUSION}

The cross-sectional econometric evidence presented here suggests that, after controlling for supply (cost) and demand-related factors affecting the profitability of operating a toxic waste treatment, storage and disposal facility, the racial makeup of a county is associated in a statistically. significant manner with the likelihood that one or more such facilities are present in the county. For the same share of each minority in the county population, the probability that TSD sites are present is highest for Asian and Pacific Islanders, followed by Other, American Indian, Eskimo and Aleut, and African-American minorities. In addition, poverty is associated positively with the odds that a facility is present, and an inverse $U$ type relationship was detected between income and TSD locations.

At the same time, Asian and Pacific Islanders are the only minority exposed to a significantly larger number of TSDs per capita at the one-percent level of significance, conditional on TSD's being present in the county. As noted earlier, this phenomenon is limited to a few states. For African-Americans the association is significant only in a one-tailed test at the 10 percent level. American Indians and 
Other minorities are not exposed to a greater number of facilities per capita than non-minorities, conditional on at least one facility being present.

\section{ENDNOTES}

1. Employment data are by industry as defined by the U.S. Census Bureau for the 1990 Census of Population. Agricultural employment includes agricultural crop and livestock production, veterinary services, landscape and horticultural services, agricultural services, forestry, and fishing, hunting and trapping. Military employment includes only members of the army.

2. Because of endogeneity, an instrumental variables estimator is used. The estimation procedure is described in a note to the Appendix Table. A better county-level measure of land costs is not available to our knowledge. However, together with population density, income per capita and urban/rural status as controls, $M H V$ is likely to provide a reasonable approximation.

3. In addition, as a reviewer pointed out, insurance costs to operators are likely to be higher; alternatively, higher population density may be associated with higher total output of goods requiring TSD facilities (independently of the industrial mix), which would imply a positive effect of this variable. Whether the net effect is positive or negative is answered empirically.

4. It would be preferable to use volume of toxic waste stored or disposed of per unit of time to measure intensity of exposure. However, such data are not available and number of sites per capita are used instead.

5. LIMDEP $^{\circledR}$ was used to carry out the estimation.

6. Black-and-white county-level maps showing shares of each minority group, poverty rates, and TSD facilities per million population and per thousand square miles are available from the senior author upon request.

\section{REFERENCES}

Been, Vicki. "Locally Undesirable Land Uses in Minority Neighborhoods: Disproportionate Siting or Market Dynamics?" Yale Law Journal 103 (1994): 1383-1422.

Blomquist, Glenn C., Mark C. Berger, and John P. Hoehn. "New Estimates of Quality of Life in Urban Areas." American Economic Review 78 (1988): 89 107.

Brown, Alice L. "Environmental Justice: New Civil Rights Frontier." Trail, 29 (1993): 48-53. 
Cropper, Maureen L., and Wallace E. Oates. "Environmental Economics: A Survey." Journal of Economics Literature 30 (1992): 675-740.

Deacon, Robert T. and Perry Shapiro. "Private Preference for Collective Goods Revealed Through Voting on Referenda." American Economic Review 65 (1975): 943-55.

Dorfman, Nancy S. "Who Will Pay for Pollution Control?-The Distribution by Income of the Burden of the National Environmental Protection Program." National Tax Journal 28 (1975): 101-115.

Fischel, William A. "Determinants of Voting on Environmental Quality: A Study of New Hampshire Pulp Mill Referendum." Journal of Environmental Economics and Management 6 (1979): 107-118.

Gianessi, Lenord P., Henry M. Peskin, and Edward N. Wolff. "The Distributional Effects of Uniform Air Pollution in the United States." Quarterly Journal of Economics 93 (1979): 281-301.

Goetz, S.J., D.L. Debertin and A. Pagoulatos, "Human Capital and Environmental Quality," University of Kentucky, Department of Agriculture Economics, mimeo, March 1995.

Hahn, Robert W., and Robert N. Stavins. "Economic Incentives for Environmental Protection: Integrating Theory and Practice." American Economic Review 82 (1992): 464-8.

Helfand, Gloria E. "Standards versus Standards: The Effects of Different Pollution Restrictions." American Economic Review 91 (1991): 622-34.

Keeva, Steve. "A Breath of Justice." ABA Journal 80 (1994): 88-92.

Mohai, Paul, and Bryant Bunyan. "Race, Poverty, and the Environment." EPA Journal 18 (1992): 6-8.

Nelson, Richard R., and Edmund S. Phelps. "Investment in Humans, Technological Diffusion, and Economic Growth." American Economic Review 56 (1966): 69-75.

Padgett, David A. "Assessing the Safety of Transportation Routes for Hazardous Materials." Geo Info Systems 2 (1992): 46-48.

Schultz, Theodore W. "The Value of the Ability to Deal with Disequilibria." Journal of Economic Literature 13 (1975): 827-64.

Selden, T.M., and D. Song. "Environmental Quality and Development: Is there a Kuznets Curve for Air Pollution Emissions?" Journal of Environmental Economics and Management 27 (1994): 147-62.

United Church of Christ. "Toxic Wastes and Race in the United States." Commission for Racial Justice, New York, N.Y.: Public Data Access Inc., 1987.

U.S. Department of Commerce. Statistical Abstract of the U.S., 1993. 113th edition, 1993. (Washington, D.C.: Bureau of the Census). 
U.S. Environmental Protection Agency. "Environmental Equity: Reducing Risk for all Communities" (Vols. 1 and 2). Washington, D.C., EPA230-R-92008/-008A, June 1992.

U.S. Environmental Protection Agency. "Catalogue of Hazardous Waste Database Reports," 1993. (Washington, D.C., EPA530--B-94-001).

Weintraub, Irwin. "Fighting Environmental Racism: A Selected Annotated Bibliography." Electronic Green Journal 1 (1994). Internet address: gopher.uidaho.edu. 
APPENDIX TABLE

Descriptive Statistics for TSD Facilities Locations

\begin{tabular}{|c|c|c|c|c|c|}
\hline \multirow[b]{2}{*}{ Variable } & & \multicolumn{2}{|c|}{ Entire sample $\left(n_{1} \cup n_{2}\right)$} & \multicolumn{2}{|c|}{ Sub-sample $\left(n_{1}\right)$} \\
\hline & & Mean & Std. Dev. & Mean & Std. Dev. \\
\hline \multirow[t]{8}{*}{$\overline{\Sigma_{i j} I N D_{i j}}$} & Paper \& Allied Products (D.V. $=0,1)$ & 0.391 & 0.488 & 0.655 & 0.476 \\
\hline & Petroleum \& Coal Products (D.V. $=0,1$ ) & 0.269 & 0.443 & 0.500 & 0.500 \\
\hline & Primary Metals Industries (D.V. $=0,1)$ & 0.412 & 0.492 & 0.682 & 0.466 \\
\hline & Fabricated Metals Products (D.V. $=0,1$ ) & 0.705 & 0.456 & 0.904 & 0.295 \\
\hline & Machinery, excl. elect. (D.V. $=0 ; 1)$ & 0.814 & 0.390 & 0.952 & 0.213 \\
\hline & Transport. Equipment (D.V.=0,1) & 0.423 & 0.494 & 0.664 & 0.472 \\
\hline & Military employment (per 100 popl.) & 0.400 & 1.896 & 0.794 & 2.799 \\
\hline & Agricultural employment (per 100 popl.) & 3.690 & 3.925 & 1.954 & 1.939 \\
\hline$M H V_{i}$ & Median Housing Value (\$, predicted) $\dagger$ & 53,490 & 30,896 & 66,595 & 37,101 \\
\hline$H I W Y_{i}$ & Interstate Access $(\mathrm{D} . \mathrm{V} .=0,1)$ & 0.405 & 0.491 & 0.619 & 0.486 \\
\hline RAILi & Railroad Access (D.V. $=0,1)$ & 0.629 & 0.483 & 0.817 & 0.387 \\
\hline$U R B N_{i}$ & Metropolitan Area (D.V. $=0,1)$ & 0.239 & 0.427 & 0.485 & 0.500 \\
\hline DENS & Population Density (persons $\mathrm{x} \mathrm{mi}{ }^{-2}$ ) & 232.0 & $1,639.5$ & 461.1 & $2,492.1$ \\
\hline \multirow[t]{6}{*}{$\Sigma_{i k} E D U C_{i k}$} & High School Dropouts $\ddagger$ & 0.159 & 0.048 & 0.153 & 0.042 \\
\hline & High School Diploma & 0.343 & 0.062 & 0.337 & 0.066 \\
\hline & Some College & 0.164 & 0.048 & 0.175 & 0.044 \\
\hline & Associate's Degree & $0.05 \hat{\jmath}$ & 0.021 & 0.058 & 0.019 \\
\hline & Bachelor's Degree & 0.090 & 0.042 & 0.104 & 0.046 \\
\hline & Graduate/Professional Degree & 0.045 & 0.027 & 0.056 & 0.032 \\
\hline \multirow[t]{2}{*}{$I N C_{i}$} & Income/capita (\$) & 11,124 & 2,681 & 12,367 & 2,920 \\
\hline & Income/capita squared $(\$ / 1,000)$ & 130,920 & 73,023 & 161,450 & 85,854 \\
\hline \multirow[t]{4}{*}{$\Sigma_{i l} R A C E_{i l}$} & African-American (share of population) & 0.086 & 0.144 & 0.094 & 0.129 \\
\hline & American Indian & 0.015 & 0.060 & 0.011 & 0.046 \\
\hline & Asian/Pacific Islander & 0.006 & 0.013 & 0.011 & 0.019 \\
\hline & Other minority & 0.018 & 0.046 & 0.020 & 0.043 \\
\hline POV $_{i}$ & Poverty Rate (popl. share below poverty) & 0.167 & 0.079 & 0.142 & 0.066 \\
\hline
\end{tabular}

Data sources: U.S. Department of Commerce.

†Median housing value was predicted from an auxiliary regression, which included an indicator variable for each state, population density, income, minority shares, urbanization codes, average age of the home and TSD facilities. These results are available from the authors upon request.

¥The educational attainment data are from the 1990 U.S. Census and represent the share of persons in each category per population 25 years and older. The excluded category is individuals with less than a ninth grade education. 